\title{
Challenges of the Targeting Approach to Social Protection: An assessment of the Ghana Livelihood Empowerment against Poverty Programme in the Wa Municipality of Ghana
}

\author{
Fauster Agbenyo \\ University for Development Studies, Wa Campus, Ghana \\ *fagbenyo@uds.edu.gh \\ Sylvester Zackaria Galaa \\ University for Development Studies, Wa Campus, Ghana \\ and \\ Gilbert Abotisem Abiiro \\ University for Development Studies, Wa Campus, Ghana \\ DOI//http://dx.doi.org/10.4314/gjds.v14i1.2
}

\begin{abstract}
Global debates on social protection have raised concerns about the appropriateness of the targeting approach for better inclusion. This study contributes to these debates by exploring the specific challenges associated with the targeting mechanism adopted by the Ghana Livelihood Empowerment against Poverty (LEAP) programme within the Upper West Regional programme district of Wa Municipality of Ghana. Qualitative data on beneficiaries' perceptions and experiences with the LEAP programme were collected through in-depth interviews with 30 LEAP beneficiaries and key informant interviews with three LEAP implementers. The findings reveal widespread perceptions of inclusion errors associated with the targeting approach adopted by LEAP. These perceived inclusion errors are as a result of lack of transparency in the handling of procedures, political interference in the selection process and poor data on household's poverty statuses. Unintended consequences of the approach include poverty-labeling, stigmatization and envy of beneficiaries leading to hatred and conflicts which are capable of destroying social cohesion in rural beneficiary communities. A sense of beneficiary powerlessness to question the 'ills' in the operations of programme is also a challenge inherent in the targeting approach. To ensure effective targeting, there is the need for education to be provided on the purpose, selection process and benefits of the programme, particularly, at the community level. There is also the need to strengthen the monitoring of the selection process. It is important that
\end{abstract}


civil society organizations provide complementary interventions to empower beneficiaries to demand for their entitlements from the programme.

Keywords: Social Protection, Cash Transfers, Targeting Approach, Challenges, Livelihood Empowerment against Poverty, Ghana

\section{Introduction}

Social protection has widely been recognized as a means of overcoming social exclusion and promoting poverty reduction (Pierson, 2007). Available literature shows that the poor in society, which can be found at the individual, household, group and neighborhood levels, are those who are often faced with the highest risk of exclusion from some components of social security interventions (Muddiman, 1999a; Muddiman, 1999b; Pierson, 2007). Thus, social exclusion and poverty are often mutually reinforcing to impact negatively on the disadvantaged in society. As a result, the last two decades have seen a number of states, particularly those in sub-Saharan Africa, demonstrating keen interest in the formulation and implementation of social protection programmes as a strategy for fighting poverty (Barham \& Maluccio, 2009; Slavin, 2009; Handa et al., 2012). Some scholars have argued that

...part of the explanation [to this heightened resort to social protection programmes] is to be found in a growing recognition that social protection can be functional to the achievement of bigger development objectives, including even economic growth and the Millennium Development Goals (MDGs). Mounting evidence that well-designed social transfers can contribute to poverty reduction is appealing to development economists and policymakers (Devereux \& Wheeler, 2007: 1).

Social protection is a system in which the state or civil society puts in place a social safety net to cater for the marginalised and vulnerable in society (Chapman, 2006; De la Brière \& Rawlings, 2006; Pierson, 2007; Slavin, 2009). Theoretically, social protection and its associated concept "social inclusion" take their roots from their opposing concept "social exclusion". Social exclusion is associated with the manifestations of poverty, lack of resources, marginalization, incapability, no entitlements, powerlessness and livelihood failures (Cameron, 2006; Pierson, 2007; Mathieson et al., 2008; Rawal, 2008; Robeyns, 2011). Social protection can therefore be conceptualized, as a process of integrating the interest of the poor, excluded, vulnerable and marginalised into the functioning areas of society. These functioning areas have been identified as the labour market, economy, society, culture, citizenship, education, health and income groups (Chapman, 2006; De la Brière and Rawlings, 2006; Slavin, 2009). According to García and Gruat (2003), social protection is: 
a set of public measures that a society provides for its members to protect them against economic and social distress that would be caused by the absence or a substantial reduction of income from work as a result of various contingencies (sickness, maternity, employment injury, unemployment, invalidity, old age, and death of the breadwinner); the provision of health care; and, provision of benefits for families with children" (García \& Gruat, 2003: 13-14).

Social grants or cash transfers according to Abbey et al. (2014) are widely acknowledged as one of the many tools for implementing social protection programmes. Samson et al. (2006), define cash-based social transfers as regular non-contributory payments of money provided by government or non-governmental organisations to individuals or households, with the objective of decreasing chronic or shock-induced poverty, addressing social risk and reducing economic vulnerability. Social cash transfers, therefore, have the potential of directly tackling income poverty and its implications for the realization of broader development objectives.

Available literature shows that social policy reform has involved choices about whether the core principle behind social protection should be "universalism" where everyone within a category - such as children or the elderly - is eligible to receive benefits from an intervention or "targeting", where benefits are explicitly targeted at people who are identified as extremely poor or vulnerable (Mkandawire 2005, Marshall \& Hill, 2014). Current social protection debates, therefore, focus on the appropriateness of these two approaches for better inclusion.

Within a universalist approach, social protection services are provided to everybody as a right, through public or private institutions (Danson et al., 2012). It is argued that the non-discriminatory nature of universal services ensure that beneficiaries of such interventions are less exposed to any humiliating loss of status, dignity or self-respect while the probability of creating a sense of inferiority, pauperism, shame or stigma among beneficiaries, is avoided (Titmuss, 1968 cited in Anttonen et al., 2012). For Titmus (1974), this model promotes the redistribution of available resources overtime. The Economic Policy Research Institute (EPRI), (2011) adds that within universal programmes, benefits are regarded as entitlements to citizens; hence such programmes are capable of building social cohesion. They, therefore, receive greater public support because of the larger and more influential population benefiting from them (Barnet et al. 2004). Despite these advantages, universal programmes require a larger funding budget for implementation which often overstretches the fiscal limits of governments (Barnet et al., 2004, Mkandawire, 2005). Mkandawire (2005) argued that, there is usually a gap between its universalist proclamations and the actual reach of its policies. He stressed that what had been touted as policies that would eventually encompass the whole society appears as exclusive privileges captured by a few in privileged sectors bent on blocking 
the extension of these programmes to other sections of the population. It is against this background that Mkandawire (2005) reported that although in the 1960s and 1970s, the leaning was towards universalistic policies, the balance has radically tilted in favour of targeting in both developed and developing countries since the 1980 os.

Targeting as an approach to social protection is the situation where specific individuals or groups are selected as beneficiaries of a social intervention based on certain common characteristics or predetermined criteria (Neil, 2001). Within the targeting approach, beneficiaries could be selected "through means tests, income tests, claw-back taxes, diagnostic criteria, behavioural requirements, and status characteristics" (Gilbert, 2001: xviii). Barnet et al. (2004) noted that targeting is more efficient, less costly and higher in quality. Similarly, the EPRI (2011) indicated that targeting potentially saves money by reducing the "inclusion error" of universal programmes - the distribution of transfers to people who are not poor. Effective targeting makes sure scarce resources go to those who need them most. In addition to the potential fiscal savings offered by targeting, EPRI (2011) argued that there are two other possible indirect benefits. First, the perceptions by policy-makers and the public's perceptions of the targeting mechanism may improve political acceptance of the programme and second, when conditions constitute the basis of targeting, the effects may be socially productive. Barnet et al. (2004) argued that because they serve relatively smaller numbers with the greatest needs, targeted programs can focus on quality. They do not dilute quality by spreading resources too thin. Thus, targeted programmes are more likely to provide the intensity and duration of services required by people with the greatest needs. The relatively smaller budget required by a targeted programme makes them more affordable and, therefore, more likely to be fully funded by the public. The public is more willing to pay for services when families cannot afford to purchase these on their own (Barnet et al., 2004).

Notwithstanding the above advantages of targeting, the approach is not without pitfalls. Mkandawire (2005) argued that the use of targeting involves some mechanisms that discriminate between the poor and the non-poor. As such, it always runs the danger of committing either type I error, which occur when someone who deserves the benefits is denied them (underpayment, false positives), or type II error, which occur when benefits are paid to someone who does not deserve them (overpayment, leakage). These are also referred to as 'the inclusion and exclusion error' (EPRI, 2011). The inclusion error is the mistake of providing the social transfer to someone in a household who is not poor whilst the exclusion error is the failure to provide a transfer to a targeted household which is poor. A second problem associated with targeting is administrative cost. There are many ways of targeting benefits, but they all require people, skills, time and money. A means test, for example, will require the repeated verification of the income or assets 
of households in order to decide whether they should receive benefits. The dynamics of poverty in many countries significantly increases the cost of targeting (EPRI, 2011).

Targeting is noted to have significant social costs. Social costs from targeting can include stigma, possible deterioration of community cohesiveness, and the potential erosion of informal support networks. In the words of Mkandawire, "the process of means-testing or identifying the "deserving poor" is often invasive and stigmatising" (Mkandawire, 2005: 14). It is argued that targeted programmes can be of poor quality because "programmes for the poor tend to be poor programmes" (Barnet et al., 2004: 4).

Drawing from the existing literature, it is clear that, at the global level, the advantages and disadvantages of the two main approaches to social protection have been debated and documented. However, this broad global evidence, often, does not reflect the reality within certain specific local contexts where such social protection policies are implemented. There is therefore the need for a detailed context-specific exploration of the advantages and disadvantages of approaches to social protection in order to inform context-specific policy reforms. This paper seeks to specifically contribute to the broader evidence on the targeting approach by exploring the specific challenges associated with the targeting mechanism adopted by the main social protection intervention policy of Ghana, the Ghana Livelihood Empowerment against Poverty (LEAP) programme.

\section{The Livelihood Empowerment against Poverty Programme as a Strategy for Social Protection in Ghana}

In demonstrating its commitment to fighting poverty and protecting the vulnerable and marginalized in society, the Government of Ghana has, since 2007, crafted and is currently implementing a National Social Protection Strategy (NSPS) (Abrebrese, 2011; Jaha \& Sika-Bright, 2015). Typical of these social protection interventions is the LEAP (Abebrese, 2011). According to the Ministry of Gender, Children and Social Protection (MGCSP) (2014), the aim of the Ghana social protection programme is "to create an allinclusive society through the provision of sustainable mechanisms for the protection of persons living in situations of extreme poverty, vulnerability and exclusion" (MGCSP, 2014:1).

Among the Social Protection programmes, the LEAP is both a targeted and a conditional cash transfer (CCT) programme, introduced in 2008, as a fundamental component of the Ghana's NSPS (MGCSP, 2014). A conditional social cash transfer programme is a programme in which the beneficiaries meet some conditions for continuous stay on the programme, while targeting has to do with meeting certain criteria for inclusion into the programme (de la Briere \& Rawlings, 2006; Lindert et al., 2007; Slavin, 2009).

The target beneficiaries of the LEAP are extremely poor households in Ghana. Extreme poverty has been defined by the Ghana Statistical Service (GSS) (2014) as those whose 
standard of living is insufficient to meet their basic nutritional requirements even if they devoted their entire consumption budget to food. This definition is in line with the United Nation's (1995) view of extreme poverty as a condition characterized by severe deprivation of basic human needs, including food, safe drinking water, sanitation facilities, health, shelter, education and information. LEAP beneficiary households are often poorer than the national rural average, with 51 percent falling below the national (upper) poverty line and a median per capita daily expenditure of approximately 85 United States Cents (Handa \& Park, 2012).

The specific eligibility criteria include households with members in at least one of the following three demographic categories: single parent with orphan(s) or vulnerable child, elderly poor, persons with extreme disability and unable to work (MGCSP, 2014). The national LEAP implementation committee selects a number of communities within a district using district poverty maps as eligible beneficiary communities. A Community LEAP Implementation Committee (CLIC) carries out a community level selection of those households who meet the LEAP membership eligibility criteria. The lists compiled at the community level as potential beneficiaries are later verified centrally with a proxy means test before registration by the Department of Social Welfare as LEAP beneficiaries.

The social grant from the LEAP programme includes cash transfer through the Ghana Post Office and free health insurance membership. The cash paid to each beneficiary household has recently been increased from a range of $\mathrm{GH} \bigotimes 8.00$ to $\mathrm{GH} \otimes 15.00$ per month in 2008 to GH $\$ 64.00$ - GH $\$ 106.00$ (1.00 US Dollar is approximately GH $\$ 4.00$ ) per month, as at September, 2015. The current transfer payment structure is as follows: GH $\$ 64.00$ to households with one eligible beneficiary; GH $\$ 76.00$ to households with two eligible beneficiaries; $\mathrm{GH} ₫ 88.00$ to households with three eligible beneficiaries; and GH $₫ 106.00$ to households with four or more eligible beneficiaries (Ghana Business News, 2015). LEAP beneficiaries and their caretakers are expected to spend the money on basic needs such as food, clothing, shelter, education and health care. The free health insurance component of the programme covers the full cost of the premium and initial registration fees with the Ghanaian National Health Insurance Scheme and the full cost of annual renewal of membership. To continue to benefit from the LEAP programme, recipients of the cash transfer must ensure that the births of all their children are registered, all children of school going age are enrolled in school and that they are registered with the National Health Insurance scheme and this constitutes the conditional aspects of the programme. The programme currently covers over 116,0oo households in 180 districts across Ghana (Terkper, 2015).

The programme is funded from general tax revenue, donations from the Department for International Development, and a loan from the World Bank (MGCSP, 2014). It is implemented by the Department of Social Welfare in the Ministry of Employment and 
Social Welfare. Monitoring of the programme at the local level is done by a regional monitoring team led by the Regional Social Welfare Officer. For payment monitoring, this team comprises officials from Ghana Postal Service and the LEAP Management Unit (LMU) at the headquarters in Accra. Monitoring is done every two months (i.e. alongside the cash transfer) using a questionnaire designed to check whether beneficiaries are actually receiving the amounts due them and whether the cash received is being used for the intended purpose. The questionnaire is also used to obtain data on beneficiaries who have passed on to ensure that they are either removed or replaced by other members of their households. A Complaints Unit has also been established at the municipal/district level where beneficiaries can directly report any issues concerning the programme. Monitoring data obtained from the local level is submitted to the LMU in Accra for analysis and necessarily action.

Since the commencement of the LEAP programme, there has been limited feedback from beneficiaries on the programme and its adopted targeting mechanism, resulting in a dearth of knowledge on the specific challenges facing the approach to social protection within the Ghanaian context (Abbey et al, 2014; Jaha and Sika-Bright, 2015). A few studies have assessed the benefits and impacts of the programme on poverty reduction (Darko, 2011; Handa et al., 2012; Handa \& Park, 2012; Agbaam \& Dinbabo, 2014; Handa et al., 2014; and Ibrahim; Yeboah, 2014), on inequality (Handa et al., 2014), school enrollment and on the economy in general (Handa and Park, 2012; Food and Agricultural Organisation, 2013). The study of Jaha and Sika-Bright (2015) assessed challenges associated with the implementation of LEAP and not challenges of the targeting approach to social protection. Furthermore, their study explored the challenges of LEAP from an institutional (implementers) stand-point without taking on board the views of beneficiaries at the grassroots. This study, therefore, examines the challenges associated with the targeting approach of LEAP, based on programme beneficiary grass-roots' 'perceptions and experiences', in the Wa Municipality of Ghana.

\section{Methodology}

A qualitative case study design was implemented within the Wa Municipality of the Upper West Region (UWR), the youngest and poorest region of Ghana (Yin, 1994). The LEAP in the Wa Municipality was chosen for the study due to experiential knowledge of the study area, which emanated from students' field work in the area during which issues surrounding LEAP including inclusion and exclusion came up. The study is therefore a follow up on students' findings and to ensure systematic documentation on these issues in the Wa Municipality. Wa Municipality is one of the eleven districts and the only Municipality in the UWR. With a total population of 107, 214, constituting about 15.3 per cent of the regional population in 2010, seven out of every 10 people in the Municipality 
are said to be poor (GSS, 2014). Poverty in the Municipality is wide spread and the most affected are women, farmers, children and the aged (Development Planning Unit of Wa Municipal Assembly, 2015). The aged constitutes 6.3 per cent and the disabled $2.6 \%$ of the municipal population. Desertions, non-engagement in any productive work and alcoholism are some issues of social protection confronting the aged in the Wa Municipality (Development Planning Unit of Wa Municipal Assembly, 2015).

The qualitative case study design enabled the researchers to explore and understand the meanings the programme beneficiaries held about issues of targeting and the context-specific challenges they experience with regard to the targeting mechanism adopted by the LEAP programme within the Wa Muncipality (Yin, 1994; Patton, 2002; Creswell, 2009). The data were collected in December, 2015, from beneficiaries of LEAP in two of the five beneficiary communities within the Wa Municipality. A simple random sampling technique was used to select the two beneficiary communities. The sampled communities were Kpongu and Tampiani. The total number of LEAP beneficiaries in these communities was eighty-eight. As a qualitative study, the exact sampled size was determined by meaning saturation (Patton, 2002).

Data were collected from 30 respondents, comprising 15 from each community, which signalled points of saturation. Even though the programme focused on both households and individuals, the study was more interested in individual beneficiaries since the experiences are mainly at the individual level. The assembly persons of the two communities assisted the research team to recruit eligible beneficiaries for the study. In order to complement the opinions of community beneficiaries, the Regional and Municipal Social Welfare Officers and the Municipal Planning Officer, were purposively sampled to serve as key informants. As the local level implementing and monitoring officers of the programmes, these key informants interact with the project beneficiaries and non-beneficiaries in the communities on a regular basis and hence were deemed capable of providing the research team with valuable additional information on beneficiaries and potential beneficiaries' experiences and perceptions about the programme. Their responses were mainly used as a means of triangulation to confirm and/or elucidate community beneficiaries' views, in order to strengthen the content validity of the study (Patton, 2002).

The main method of data collection was semi-structured interviews. This method allowed for in-depth interviews and probing for detailed information on the programme. The interview guide covered topics including basic characteristics of the respondents, their understanding of the programme and its modalities, their perceptions and experiences with the selection process, awareness of their entitlements from the programme, the adequacy of cash payments of the programme, utilisation of cash received and general perceptions about the challenges of the targeting approach of 
the programme. The interview guide was pre-tested with five beneficiaries before actual data collection. Two trained research assistants assisted the research team to conduct the interviews with community beneficiaries in the local language (Wale) and with the two programme implementers in English. The interviews with programme beneficiaries were conducted at the beneficiaries' homes and that of the implementers at their respective offices. All responses were directly tape-recorded alongside detailed handwritten notes taken by the research assistants. Informed consent was obtained from all respondents before interviews and tape-recording. All respondents were assured of the confidentiality of their responses and their freedom to opt out of the study.

The tapes were transcribed and the data from beneficiaries were translated into English language for analysis. The analysis was fully manual. The analytical approach was basically thematic and coding was largely inductive (Patton, 2002). For the purpose of analytical triangulation, two of the authors read the transcripts and notes, and coded them independently. At a later stage in the analysis, the two analysts brought their work together for comparison and reconciliation of conflicting codes. Discrepancies were reconciled by referring to the original text. The codes (themes) agreed upon by the two analysts were categorised into main themes and sub-themes. Quotations that vividly illustrated the themes of the study were selected from the transcripts to support the results.

\section{Results}

The key findings that emerged from the analysis of data on perceptions and experiences of LEAP beneficiaries and corroborated by local level programme implementers and monitors are described under the following themes: perceptions on beneficiaries' selection, beneficiaries' awareness of their entitlements from the programme, uses of the cash received by beneficiaries, and unintended consequences of targeting, manifesting in a low perceived image of beneficiaries and hence their powerlessness to question the adequacy of benefits, poverty-labeling, envy and stigmatization of beneficiaries.

\section{Perceptions about the Selection Process}

Majority of the interviewees (18 out of 30) initially reported that the selection procedure was transparent whiles the others thought otherwise. However, an in-depth probing into this issue revealed that even some of those who held positive views about the selection process were only conjecturing transparency of the process but in reality did not understand how and why they themselves were selected as beneficiaries instead of other community members thought to be equally poor. Those who openly expressed doubts about the transparency of the selection process emphasised that they did 
not understand why some of the people who were initially selected by the CLICs at the community level were not included in the final lists of beneficiaries. Some argued that their lack of understanding about the selection process resulted from the fact that the entire selection procedure was not explained to them.

I think the selection process is transparent; [....] But honestly, I do not know the basis for my selection while others whose names were written and pictures taken were not selected. (Woman LEAP beneficiary from the Kpongu community, December, 2015).

The Municipal and Regional Social Welfare Officers also confirmed beneficiaries concerns about the transparency of the selection process and further explained that the opinions of non-beneficiaries of the programme was that the final selection was based on political affiliations. These monitoring officers however argued that these concerns resulted from beneficiaries little knowledge about the selection process used by the programme.

During our disbursement and monitoring of the use of cash disbursed to beneficiaries and where we have the opportunity to interact with both beneficiaries and non-beneficiaries of the programme, there is a general dissent among the non-beneficiaries of the programme, especially those whose names were part of the initial lists that were sent to Accra during the selection process, that they were dropped because of their political affiliation... I mean because they do not belong to the ruling National Democratic Congress (NDC); something I personally find to be worrying (Municipal Social Welfare Officer, Wa, December, 2015).

What has come out many times during our monitoring visits, both at the community levels and interaction with the CLICs is that those who were dropped from the original list as part of the selection process and also some who feel they are either poorer or just as poor as those enrolled onto the programme did not make their way onto the programme because they don't belong to the ruling National Democratic Congress (NDC) party or no proper information was given about their loyalty to the party. This is unfortunate and it is all born out of ignorance or lack of enlightenment about the program. (Regional Social Welfare Officer, Wa, December, 2015).

We have reports about some local politicians who short circuited [sic] and ended up distorting the actual process the programme designers have put in place from the national level. (Regional Social Welfare Officer, Wa, December, 2015). 
The Municipal Officer gave an insight into what might have been responsible for the dropping of some people from the final selection process and probably the erroneous inclusion of people who were thought to be relatively less poor compared to other community members. He argued that it might have resulted from the provision of false information by potential beneficiaries about their households in order to be enrolled onto the programme.

I sometimes get surprised; but well, I can understand that due to the general poverty situation people provided misleading information about the status of their households all in a bid to be enrolled in [sic] the programme. When you cross-check and find out the true status of some of the households, you are amazed. (Municipal Social Welfare Officer, Wa, December, 2015).

The Municipal Social Welfare Officer also acknowledged that due to inadequacy of funds for the upscaling of the programme, not all eligible beneficiaries have been covered by the programme. The inadequate funding has resulted in the adoption of a quota system which often cuts off substantial number of eligible beneficiaries from being enrolled on the programme.

Perhaps due to the numerous competing needs of the country [....]. I see the funds that come from the national level as inadequate and limited. It is unable to cover all the people one would have thought are poor enough and should be a part of the programme. This does not necessarily mean they have been discriminated against or unfairly treated.(Municipal Social Welfare Officer, Wa, December, 2015).

\section{Beneficiaries' Awareness about Their Entitlements from the Programme}

There was high level of awareness among beneficiaries about the cash transfer component of the programme. All respondents reported that the LEAP benefits package included regular cash transfer to them and unanimously acknowledged receiving cash often ranging from $\mathrm{GH} \$ 48.00$ and $\mathrm{GH} \$ 90.00$ from the programme. In relation to the health insurance component, majority (22 out of 30) of the beneficiaries were also aware of their free automatic membership entitlements to the NHIS whilst a few reported that they were not aware. However, some of those who reported knowledge of their free entitlement to NHIS membership indicated that they were not aware that it included annual renewal of the membership card.

I remember at one of the meetings with the officer, the man indicated that our benefits included not only the cash transfer but also free access to the NHIS card; but I did not hear him talk about periodic renewal of the card. (A female LEAP beneficiary from Tampiani community, December, 2015). 
Consequently, a substantial number of respondents (about 30\%) had to pay on their own for the renewal of their NHIS cards when they expired. Some of those who reported to have been aware that the NHIS renewal was covered by LEAP still made out-ofpocket payment for the renewal due to delays on the part of the LEAP to renew the cards for them. Apparently, those who fell sick before the delayed renewal of the NHIS subscription had to pay for renewal of their cards before they could visit the health facility.

I paid four Ghana Cedi [sic] for the renewal the last time my card expired before I was able to attend the hospital when I was sick. (Woman LEAP beneficiary from Tampiani community, December, 2015).

I am aware and registered for the NHIS as they promised us during the meeting that day [....]. It has benefited me by increasing my access to healthcare. ... I have always paid for the renewal of the card myself. LEAP never renewed the NHIS card for me". (Woman beneficiary from Tampiani community, December, 2015).

The interview with the Regional Social Welfare Officer confirmed the challenges associated with the renewal of the NHIS membership cards as expressed by the beneficiaries. The officer, however, attributed it to poor accessibility of beneficiary communities especially during the rainy season due to the poor nature of roads. The officer argued that this also partly increases the selection error, particularly when the selection is taking place at a time when some communities are inaccessible.

\section{Uses of the Cash received by Beneficiaries}

As intended by the programme, majority ( 28 out of 30 ) of the beneficiaries intimated that they mainly spend their cash on buying food to feed their families and the education of their children. They argued that the cash they receive enables them to pay school fees, buy books, pencils and shoes for their wards in school. Other uses of the money as were reported by some respondents included paying medical bills and investing in income generating activities such as farming and trading.

I use the money to buy maize to feed my family and when the children go to school and come back to ask for school fees and things like that then I use the money to pay. (Female LEAP beneficiary in Kpongu community, December, 2015).

In terms of the benefits of the free NHIS membership component of the LEAP, the beneficiaries were emphatic that it helps them to reduce their spending on healthcare services and increases their access to healthcare. Majority of the beneficiaries noted that 
this increased physical and financial access to healthcare and has contributed to saving their lives.

I was very sick. It is because of this free NHIS that I am still alive today. I would have been dead. (A male LEAP beneficiary from Tampiani community, December, 2015).

\section{Unintended Consequences of the Targeted Approach}

An in-depth analysis of the data revealed that the selective targeted approach adopted by the LEAP programme has resulted into some unintended negative consequences. These have negatively affected the perceived image of beneficiaries of the programme. The specific unintended consequences that emerged from the data analysis are described as follows:

\section{Powerlessness of LEAP Beneficiaries to Question the Adequacy of Benefits}

The beneficiaries were divided in their opinions about the adequacy of the cash they receive in meeting their daily needs. Those who viewed the amounts to be insufficient argued that it was not enough to meet the rising cost of living in the country. An indepth probe into those who reported the adequacy of the amount, however, revealed a sense of powerlessness in them to question the adequacy of the benefits since such benefits were perceived as free cash offered to them in the form of a gift.

It is not enough; but if you were sitting and they came to give you help and it is not enough, you can't say that it is not enough. (Male LEAP beneficiary from Tampiani community, December, 2015).

If you are sitting down and someone comes to give you a gift, you cannot say it is not enough (LEAP beneficiary in Kpongu community, December, 2015).

You know, it is a normal help that they give us and whether the money reach or does not reach your needs, you don't have anything to say. When you sit down and you don't have anything and someone comes to give you help; even though it is not enough, [but cf.] you don't have anything to say so far as it is a help. (A woman LEAP beneficiary in the Kpongu community, December, 2015).

Once we don't work for it, we can't say it is not enough. (LEAP beneficiary in Tampiani, December, 2015). 


\section{Poverty-labeling, Stigmatisation and Envy of Beneficiaries}

The beneficiaries also expressed concerns about issues of envy and stigmatization. Some beneficiaries indicated that some members of the community labeled them as 'people who cannot take care of themselves' whiles those whose names were written but were not selected as well as other potential beneficiaries tended to envy them.

Since the inception of this programme that brought money to us, some of us are referred to as 'poor people', 'weak people', 'or people who cannot fend for themselves. Even though we think this is due to envy, it gives a course for worry for some of us. (Male beneficiary from Tampiani community, December, 2015).

\section{Discussion}

This is one of the first studies that have exclusively examined the implementation challenges of LEAP as a selective targeted approach to social protection in Ghana. The key findings that emerged from our in-depth qualitative exploration and their policy implications are discussed as follows.

Firstly, the key finding that beneficiaries use the cash received from LEAP for feeding, education and medical care, is in line with findings from the programme monitoring reports and other studies within Ghana (Handa \& Park 2012; Abbey et al., 2014; MGCSP 2014). This is also supported by some evidence from other contexts that conditional cash transfer programmes such as LEAP can increase access to health services including vaccination coverage in rural Nicaragua (Barham \& Maluccio, 2009). The findings therefore support the MGCSP's (2014) assertion that LEAP enables households to survive and meet their basic food needs and also increases school enrolment and regular attendance. It can thus be deduced that the immediate impact of the programme is being met as noted by Handa and Park (2012).

Besides, the evidence that some beneficiaries invested part of the money into their business activities also reinforces the view that social transfer grants can have a long term effect on overall economic growth (MGCSP, 2014). This can be viewed as the overall intended impact of a targeted approach as it always aims at helping the very poor people to gradually graduate out of poverty (Barnet et al., 2004, Devereux \& Wheeler, 2007) and hence eventually ensure an inter-generational break from the cycle of poverty within such households.

However, as typical of targeted social protection programmes, the findings from this study revealed the potential existence of inclusion and exclusion errors in the LEAP programme (Mkandawire, 2005; EPRI, 2011). The evidence of beneficiaries' 
dissatisfaction with the selection procedure in terms of transparency is a pointer of possible selection errors. It was striking that some programme beneficiaries doubted the transparency of the process and clearly stated that they did not understand why they were selected over and above other equally perceived poor people within the community. The programme implementers' confirmation of non-beneficiary's views about similar widespread perception of political favoritism in the selection process strengthened the evidence of potential selection bias. Beneficiaries' knowledge concerning nonbeneficiaries' views about them and the envy and stigmatisation of them are further indicators of widespread dissatisfaction with the selection process. It is therefore reasonable to conclude, in line with the FAO's (2013), that rural community residents would like a LEAP which covers more of the poorest in the community.

It is, however, possible that the perceived selection biases were only, errors that resulted from practical difficulties in ensuring effective targeting within such rural contexts. This argument is backed by reports of geographical inaccessibility of some households and the general difficulties in obtaining accurate data on household poverty statuses within the informal sectors of rural communities. This was evident from the reports of the provision of wrong information by respondents on their poverty statuses; which probably resulted in their later exclusion from the programme after verification at the regional and national levels.

It is also practically difficult to achieve the wider coverage envisaged by the community members due to insufficient funding which necessitated the adoption of a quota system and subsequent exclusion of some eligible beneficiaries. It is, therefore, possible that the widespread perception of selection problems could only be due to these practical difficulties or the lack of understanding about the recruitment process. To clearly ascertain the veracity of these perceived inclusion errors, additional studies estimating the socio-economic characteristics of the beneficiaries relative to non-beneficiaries and further qualitative exploration of the views of both beneficiaries and non-beneficiaries on the selection process are needed. The findings from the study, therefore, bring to question, the effectiveness of the selective targeting approach in avoiding inclusion errors in social protection programmes (Barnet et al., 2004).

What is worrying is the evidence that the perceived biases in the selection of beneficiaries has resulted in unintended consequences such as the stigmatisation and labeling of recipients of the cash transfers as poverty-stricken weaklings, incapable of taking care of themselves. This humiliation does not only lead to a loss of status, dignity or self-respect of the beneficiaries (Titmus, 1968, Anttonen et al., 2012), but can potentially lead to a reduction in the patronage of the programme. In general, there is a high sense of solidarity and cohesion among rural communities in Ghana (Nunkunya, 1992). However, this envy on the part of some non-beneficiaries to the effect of creating 
a sense of inferiority, pauperism, shame and stigma of the beneficiaries (Titmus, 1968; Anttonen et al., 2012) can result in hatred and conflicts capable of destroying the social cohesion of such communities (EPRI, 2011).

Given the perception of favoritism in the selection of the beneficiaries, it was not surprising that the study revealed lack of the sense of entitlements to the benefits from the programme by the beneficiaries. Thus, the beneficiaries view entitlements to such benefits not as their right but rather a favour offered to them by the government. This general sense of lack of entitlements to the benefits from LEAP casts doubts on the ability of LEAP to empower its beneficiaries. This finding, therefore, brings to question, the ability of targeted social protection programmmes to reduce the social vulnerability of their beneficiaries. This was evident in the fact that many respondents were not satisfied with the cash they received but felt that they had no right to question it. The inadequate information provided to beneficiaries on the full benefits of the programmes also played a role in weakening the power of beneficiaries to demand the full benefits of the scheme. This therefore calls for the role of civil society organisations to strengthen the power of these beneficiaries to enable them appreciate their rights and entitlements to the LEAP benefits and hence demand for them when they are not offered (Danson et al., 2012).

It must be noted that as a qualitative study, the findings from this study are only applicable to other contexts of similar characteristics but cannot be absolutely generalisable to other settings. Besides, the limitation of the study to only LEAP beneficiaries does not give a holistic picture and hence future studies should explicitly examine the perspectives of both the beneficiaries and non-beneficiaries within communities of other districts across the Upper West Region.

\section{Conclusion}

The study has revealed challenges associated with the selective targeting approach of beneficiaries of social protection from the standpoint of beneficiaries' perceptions and experiences with the Ghana LEAP programme. Though the study has discovered that beneficiaries received and used the benefits of LEAP as intended by the programme, specific challenges of the targeted approach adopted by the programme were identified to include: widespread perceptions of inclusion and exclusion errors resulting from lack of transparency and political interferences in the selection process, inaccurate information on household's poverty status and geographical inaccessibility of some households; inadequate information on the benefits of the programme resulting in low awareness and lack of access to the full benefits of LEAP. It is, therefore, recommended that to ensure effective targeting, the activities of CLICs must be strictly monitored to 
avoid issues of bribery, corruption and politicisation in the selection of beneficiaries. Government and other stakeholders should make the effort to increase the coverage of the programme in beneficiary communities and beyond. Civil society organisations need to take keen interest in the operations of LEAP and implement a set of complementary activities such as capacity building through education to empower beneficiaries to enable them demand for their rights and entitlements from the programme. This effective education is urgently needed at the community level and should focus on the purpose, selection process and benefits of the programme.

\section{References}

Abbey, C.O., Odonkor, E. and Boateng, D. (2014). A Beneficiary Assessment of Ghana's Cash Transfer Programme (LEAP) in May 2014. African Development Programme (2014) Accra.- Ghana.

Abebrese, J. (2011). Social Protection in Ghana: An overview of existing programmes and their prospects and challenges. Germany; Friedich Ebert Stiftung.

Agbaam, C. and Dinbabo, M. F. (2014). Social grants and poverty reduction at the household level: Empirical evidence from Ghana. Journal of Social Science 39(3), pp. 293-302.

Antonnen, A., Haikio, L. and Stefansson, K. (2012). Welfare State, Universalism and Diversity. Edward Elgar Publishing Limited.

Barham, T. and Maluccio, John. (2009). Eradicating Disease: The Effect of Conditional Cash Transfers on Vaccination Coverage in Rural Nicaragua, Journal of Health Economics, 28(3), pp. 611-621.

Barnet, W. S., Brown, K. and Shore, R. (2004). The Universal vs. Targeted Debate: Should the United States Have Preschool for All? National Institute for Early Education Research.

Cameron, C. (2006). Geographies of welfare and exclusion: Social inclusion and exception. Progress in Human Geography 30 (3), pp. 396-404.

Chapman, K. (2006). Social transfers and equitable access to education and health services. Background Papers Scaling up Services Team. DFID Policy Division. January, 2006. Available at:http://www.dfid.gov.uk/pubs/files/socialtransfers-back.pdf.

Creswell, J.w. (2009). Research Design: Qualitative, Quantitative and Mixed Method Approaches. London: SAGE Publications.

Danson, M., McAlpine, R., Spicker, P. and Sullivan, W. (2012). The Case for Universalism: An assessment of the evidence on the effectiveness and efficiency of the universal welfare state. The Jimmy Reid Foundation. 
Darko, R. O. (2011). Reducing poverty through a social grants programme: The case of Ghana Institute of Statistical Social and Economic Research, Legon.

De la Brière, B. and Rawlings, L.B. (2006). Examining conditional cash transfer programmes: A role for increased social inclusion? World Bank Social Protection Discussion Paper no. 0603.

Development Planning Unit of Wa Municipal Assembly [DPU, WMA] (2015). Available at: http://mofa.gov.gh/site/?page_id=1685. Accessed: $15^{\text {th }}$ December, 2015.

Devereux, S. and Sabates-Wheeler, R. (2007). Editorial introduction: Debating social protection. Institute of Development Studies (IDS) Bulletin, Vol. 38, No. 3, p. 1.

Economic Policy Research Institute [EPRI] (2011). Designing and implementing social transfer programmes: Targeting social transfer instruments. Economic Policy Research Institute. Available at:http://epri.org.za/wp-content/uploads/2011/o1/ EPRI_Chapter8_4.pdf. Accessed: January 12, 2015.

Food and Agriculture Organization of the United Nations [FAO] (2013). Qualitative research and analyses of the economic impacts of cash transfer programmes in subSaharan Africa: Ghana country case study report. Oxford policy management.

Jaha, I. R. and Sika-Bright, S. (2015). Challenges of the livelihood empowerment against poverty in the Upper West Region of Ghana: The institutional perspective. UDS International Journal of Development. Vol. 1 Issue 2, pp. 188 - 205.

Ibrahimi, M. Yeboah, T. (2014). Combating Poverty towards Actualizing the Millennium Development Goals and Beyond: Do Cash Transfer Programmes add up to the Agenda? Journal of Economic and Social Studies. Vol. 4. No. 2, pp. $101-132$.

García, A.B. and Gruat, J.V. (2003). Social Protection: A Life Cycle Continuum Investment for Social Justice, Poverty Reduction and Sustainable Development. International Labour Office.

Ghana Statistical Service (2014). Ghana Living Standards Survey Round 6 Report: Poverty Profile in Ghana (2005-2013). Available at: www.statsghana.gov.gh/glss6.html. Accessed: February 13, 2015.

Gilbert, N., (2001). Targeting social benefits: International perspectives and trends. New Jersey: Transaction Publishers.

Handa, S., Park, M., Darko, RO, Akoto-Osei, I., Davis, B. and Daidone, S. (2014). Livelihood empowerment against poverty program impact evaluation in Ghana. 3ie Grantee Final Report. New Delhi: International Initiative for Impact Evaluation (3ie).

Handa, S. and Park, M. (2012). Livelihood Empowerment against Poverty Program: Ghana Baseline Report. Carolina Population Center: University of North Carolina at Chapel Hill. 
Handa, S., C. Huang, N. Hypher, C. Teixeira, F. V. Soares and B. Davis (2012). Targeting effectiveness of social cash transfer programmes in three African countries. Journal of Development Effectiveness. 4(1), pp. 78-108.

Lindert, K. Linder, A. Hobbs, J. and de la Brière, B. (2007). The Nuts and Bolts of Brazil's Bolsa Família Program: Implementing Conditional Cash Transfers in a Decentralised Context. World Bank Social Protection Discussion Paper. No. 0709.

Marshall, C. and Hill, P. S. (2014). Ten best resources on conditional cash transfers. Health Policy and Planning, pp. 1-5.

Mathieson, J., Popay, J., Enoch, E., Escorel, S., Hernandez, M., Johnston, H., and Rispel, L. (2008). Social Exclusion: Meaning, measurement and Experience and links to health inequalities: A review of literature. WHO Social Exclusion Knowledge Network Background Paper 1 Sept 2008.Available at: http://www.who.int/social_ determinants/media/sekn_meaning_measurement_experience_20o8.pdf.pdf. Accessed: January 12, 2015.

Ministry of Gender, Children and Social Protection. (2014). The Livelihood Empowerment Against Poverty (LEAP) Programme: Reducing Poverty and Promoting Growth in Ghana. Retrieved June 10, 2015 from www.unicef.org/ghana/gh_resources_ LEAP_briefing_paper.pdf.

Mkandawire, T. (2005). Targeting and Universalism in Poverty Reduction. United Nations Research Institute for Social Development.

Muddiman, D. (1999a), Public libraries and social exclusion: the historical legacy, Leeds: School of Information Management. Leeds Metropolitan University (Public Library Policy and Social Exclusion Working Papers no.1).

Muddiman, D. (1999b). Theories of social exclusion and the public library, Leeds: School of Information Management. Leeds Metropolitan University (Public Library Policy and Social Exclusion Working Papers no.2).

Neil, G. (2001) (Ed.). Targeting social benefits: International perspectives on issues and Trends. Rutgers: Transaction Publishers.

Nukunya, G. K. (1992). Tradition and change in Ghana: An introduction to Sociology. Accra: University of Ghana Press.

Patton, M. Q. (2002). Qualitative research and evaluation methods (3rd ed.). Thousand Oaks, CA: Sage.

Pierson, J. H. (2007). Tackling social exclusion. U.K. Routledge.

Rawal, N. (2008). Social inclusion and exclusion: A Review. Dhaulagiri Journal of Sociology and Anthropology, Vol. 2, pp. 161-18o. 
Robeyns, I. (2011). The Capability Approach. Available at: http://plato.stanford.edu/ entries/ capability-approach.

Samson, M., Niekerk, I.V. and Quene, K.M. (2006). Designing and Implementing Social Transfer Programmes. Economic Policy Research Institute.

Slavin, R. E. (2009). Can financial incentives enhance educational outcomes? Evidence from international experiments. Educational Research Review. Available at: www.elsevier. com/locate/edurev. Accessed: 02/02/2016.

Terkper, S. (2015). The budget highlights of the budget statement and economic policy. Ministry of Finance: Ghana.

Titmuss, Richard M. (1974). Social Policy: An Introduction (edited by Brian Abel-Smith and Kay Titmuss). New York: Pantheon Press.

Titmuss, Richard M. (1968). Commitment to welfare. London: Allen \& Unwin.

United Nations (1995). "Report of the World Summit for Social Development", March 6-12, 1995 .

Yin, R.K. (1994). Case study research design and methods: Applied social research and methods series. Second ed. Thousand Oaks, CA: Sage Publications Inc. 